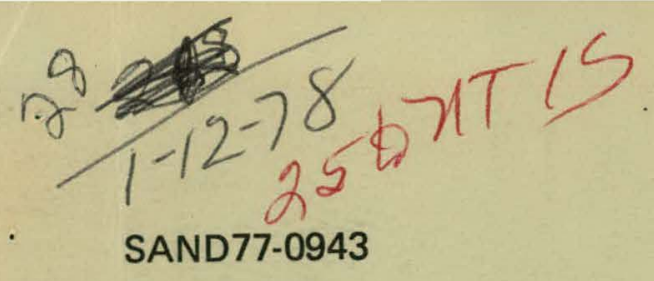

Unlimited Release

\title{
An Efficient Numerical Method for Time Independent Plasticity
}

Raymond D. Krieg

Prepared by Sandia Laboratories, Albuquerque, New Mexico 87115

and Livermore, California 94550 for the United States Department

of Energy under Contract AT(29-1)-789

Printed November 1977

\section{Sandia Laboratories}




\section{DISCLAIMER}

This report was prepared as an account of work sponsored by an agency of the United States Government. Neither the United States Government nor any agency Thereof, nor any of their employees, makes any warranty, express or implied, or assumes any legal liability or responsibility for the accuracy, completeness, or usefulness of any information, apparatus, product, or process disclosed, or represents that its use would not infringe privately owned rights. Reference herein to any specific commercial product, process, or service by trade name, trademark, manufacturer, or otherwise does not necessarily constitute or imply its endorsement, recommendation, or favoring by the United States Government or any agency thereof. The views and opinions of authors expressed herein do not necessarily state or reflect those of the United States Government or any agency thereof. 


\section{DISCLAIMER}

Portions of this document may be illegible in electronic image products. Images are produced from the best available original document. 
Issued by Sandia Laboratories, operated for the United States Energy Research and Development Administration by Sandia Corporation.

\section{NOTICE}

This report was prepared as an account of work sponsored by the United States Government. Neither the United States nor the United States Energy Research and Development Administration, nor any of their employees, nor any of their contractors, subcontractors, or their employees, makes any warranty, express or implied, or assumes any legal liability or responsibility for the accuracy, completeness or usefulness of any information, apparatus, product or process disclosed, or represents that its use would not infringe privately owned rights. 
Issued by Sandia Laboratories, operated for the United States Department of Energy by Sandia Corporation.

NOTICE

This report was prepared as an account of work sponsored by the United States Government. Neither the United States nor the Unitod States nepartment of Energy, nor any of their employees, nor any of their contractors, subcontractors, or their employees, makes any warranty, express or implied, or assumes any legal liability or responsibility for the accuracy, completeness or usefulness of any information, apparatus, product or process disclosed, or represents that its use would not infringe privately owned rights.

Printed in the United States of America Available from

National Technical Information Service

U.S. Department of Commerce

5285 Port Royal Road

Springfield, VA 22161

Price: Printed Copy: $\$ 3.50$

Microfiche: $\$ 3.00$ 
SAND77-0943

Unlimited Release

AN EFFICIENT NUMERICAL METHOD

FOR TIME INDEPENDENT PLASTICITY*

by

R. D. Krieg

SANDIA IABBORȦTORIES

ALBUQUERQUE, NEW MEXICO 87115

\begin{abstract}
A new numerical method for the solution of plasticity equations is presented. The plasticity model is a commonly used elastic-plastic strain hardening model for combined isotropic-kinematic hardening with Ziegler's modification. Thermal strains and temperature variable properties are included. The method is also specialized to the nonthermal linear strain hardening case where only two additional vector and two scalar algebraic:equations, including one square root, are needed over that needed for the elastic case. The method has roughly the same accuracy as conventional numerical treatments of the plasticity equations but requires roughly one-third as much computational time.
\end{abstract}

${ }^{*}$ This work was supported by the U.S. Department of Energy. 


\section{INTRODUCTIION}

Finite element structural computer programs are now routinely performing calculations on the elastic-plastic response of metals, e.g., [1,2]. Single runs taking several hours on large high-speed computers are becoming more common, espectally in regard to thermal problems. The computational efficiency of a constitutive equation then is both an asthetic and financial concern to a structural analyst.

A new numerical method is presented for solving time independent incremental plasticity equations. The properties are taken to be temperature dependent, but creep strains are not included. For the rase where the otop io partially elasllc and partlally piastic, the method does not require that the interface between the two be located and separate equations be applied to each region. 


\section{PRELIMINARIES}

Metals at low temperatures (generally below one third the melting temperature on an absolute scale) are modeled reasonably well by ignoring time effects such as creep and anelasticity. The strain rate tensor is assumed to be divided into elastic, plastic and thermal parts.

$$
\dot{\epsilon}=\dot{\epsilon}^{\mathbf{e}}+\dot{\dot{\epsilon}}^{\mathrm{p}}+\dot{\delta} \dot{\epsilon}^{\mathrm{T}}
$$

where $\underset{\sim}{\delta}$ is a veclur ${ }^{1}$ with unity normal rnmpnnents and zero shear. components. The elastic strain is defined as the strain which is recovered if the material is unloaded from some stress state. This unloading is approximated as a linear process given by:

$$
\dot{\boldsymbol{\epsilon}}^{\mathrm{e}}={\underset{\approx}{\mathrm{E}}}^{-1} \dot{\boldsymbol{g}}
$$

If the elastic modulus varies due to, for example, a temperature change, then the integrated form of the equation between states 1 and 2 is:

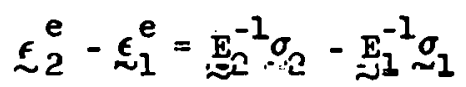

This is used in the integrated form of Eqn. (1) to give

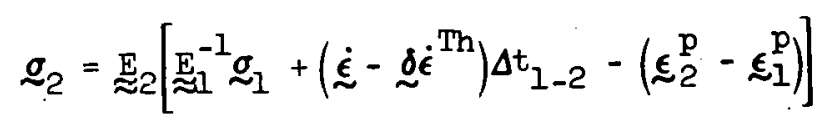

where the total strainrate and the thermal stralrrate arc assumin.] ron bc constant during the process.

1. The vector $\mathbf{E}$ for example, has components which in the tensor subscripts would be $\left[E_{x x}, E_{y y}, E_{z z}, E_{x y}, E_{x z}, E_{y z}, E_{z x}, E_{z y}\right]$. The linear transformation $\underset{\sim}{\mathrm{E}}$ could be represented as a $9 \times 9$ matrix. 


\section{Yield Surface}

A yield stress function $\varphi$ is defined as

$$
\varphi=\underset{\sim}{\xi} \cdot \underset{\sim}{\xi}-R^{2}
$$

where ${\underset{\sim}{\xi}}_{\text {is }}$ is the deviatoric part of the vector $(\underset{\sim}{\sigma} \cdot \underset{\sim}{d})$ and where deviators are defined in the form exemplified by the deviator stress as

$$
\underline{\sim}=\underline{\sim}-\underset{\sim}{\delta}(\sigma \cdot \delta) / 3
$$

The radius of the yield surface $R$ and the position of the center in deviatorlc stress space may be considered as state variables. These variables are needed to describe isotropic and kinematic hardening as described in the next section.

The plastic loading condition can be defined with the usual inequalities, c.f.. Fung. [3], but numerically it is more convenient to separate the regimes as.follows. Equation. (3) is solved for the "trial stress" state, i.e., the stress state which would exist if the process were elastic. This, value is used in Eqn. (4) to find $\varphi_{\mathrm{T}}$ : If $\varphi_{\mathrm{T}} \leq 0$, the process is indeed elastic and the final stress state is the "trial" stress state. If $\varphi_{\mathrm{T}}>0$, then the process is at least partially plastic and calculation of the final stress state is more involved.

\section{Plastic Hardening Rules}

The plastic hardening rules are constructed such that the stressstrain curve for uniaxial stress is followed. The consistency condition that the stress state must lie on the surface $\varphi=0$ during a plastic process gives a starting point for the selection of hardening rules. A uniaxial form of Eqn. (4) for $\dot{\varphi} \leq 0$ is

$$
|\sigma-\bar{\alpha}| \leq \mathrm{Y}
$$


where $\bar{\alpha}$ and $Y$ are uniaxial counterparts of $\underset{\sim}{a}$ and $R$ in Eqn. (4). The stress is assumed to be described on loading by a function $H\left(e_{p^{\prime}} \theta\right)$ where $\theta$ is temperature. This function in turn is decomposed into two parts which are given by the restricted loading-only case as

$$
\begin{aligned}
& \mathrm{H}_{\alpha}\left(\bar{e}_{\mathrm{p}}, \theta\right)=\bar{\alpha} \\
& \mathrm{H}_{\mathrm{R}}\left(\bar{e}_{\mathrm{p}}, \theta\right)=\mathrm{Y}
\end{aligned}
$$

where

$$
\mathrm{H}=\mathrm{H}_{\alpha}+\mathrm{H}_{\mathrm{R}}
$$

The function $\mathrm{H}\left(\overline{\mathrm{e}}_{\mathrm{p}}, \theta\right)$ would be experimentally determined from stressplastic strain curves ar various temperatures. The separation into $\mathrm{H}_{\mathrm{R}}$ and $\mathrm{H}_{\alpha}$ is made by reversing the load direction trom some stiess given by $H\left(\bar{e}_{p}, \theta\right)$ and finding the compressive stress $\sigma_{c}$ at which reverse yield begins. Then the values of $H_{R}$ and $H_{\alpha}$ at discrete $\bar{e}_{p}$ and $\theta$ are:

$$
\begin{aligned}
& \mathrm{H}_{\mathrm{R}}=.5\left(\left|\sigma_{\mathrm{c}}\right|+\mathrm{H}\right) \\
& \mathrm{H}_{\alpha}=.5\left(-\left|\sigma_{\mathrm{c}}\right|+\mathrm{H}\right)
\end{aligned}
$$

For the full ninewdimencional stress space, the center of the yield surface is a vector and only its rate of change has a specified direction. Ziegler's modification of Prager's hardening \&ule will bc used here. The time derivative of the scalar equations are generalized as:

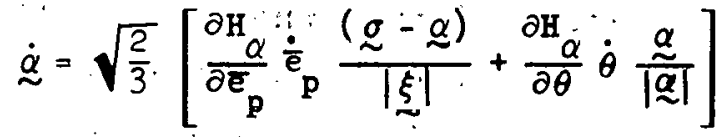

$$
\begin{aligned}
& \dot{R}=\sqrt{\frac{2}{3}}\left[\frac{\partial \mathrm{H}_{\mathrm{R}}}{\partial \overline{\mathrm{e}}_{\mathrm{p}}} \dot{\bar{e}}_{\mathrm{p}}+\frac{\partial \mathrm{H}_{\mathrm{R}}}{\partial \theta} \dot{\theta}\right]
\end{aligned}
$$


where $\dot{\bar{e}}_{\mathrm{p}}$ is the effective plastic strainrate,

The vector $(\underset{\sim}{\sigma}-\underset{\sim}{\alpha}) /|\underset{\sim}{\xi}|$ is not a unit vector as would follow from a generalization of the uniaxial stress result. This is not critical here. since only the deviatoric part of $\underset{\sim}{\alpha}$ is used and the vector is a unit vector in that restricted space. These hardening rules were suggested by Hodge [4] in the non-thermal form and described more completely by Goell and Malvern [5]. Equations for $R$ and $\underset{\sim}{\dot{\alpha}}$ are usually applied only during a plastic loading process when $\dot{\bar{e}}_{p}$ is non-zero.. For the thermal case here, integration of $\dot{R}$ and $\underset{\sim}{\dot{\alpha}}$ proceeds during temperature fluxuations even if the process is elastic.

The vector direction for $\partial \alpha / \partial \theta$ is chosen simply as the only preferred direction known to the material, since $\alpha$ could change with temperature with no applied stress. But the size of this term must be taken into consideration since the efficiency of the model falls drastically if this one term cannot be approximated.

An Approximation for $\partial \alpha / \partial \theta$

Phillips and Tang [6, fig. 6] have observed experimentally that both the radius of the yield surface and its center location vary with temperature in pure aluminum. This variation was observed to be reversible, which seems to verify the forms of Eqns. (8) and (9). Unfortunately, the very small strain definition of yield necessary for the experiments is a rather poor value for fitting a theory of the type described here. Hecker [7] shows that if a larger strain deflnition of yield is used, then the material is more isotropically and less kinematically hardening. The small strain definition also gives very complicated yield surfaces. This complicates the above statement concerning $\partial \alpha / \partial \theta$. If the transverse extremes of the yield surface were said to locate $\underset{\sim}{\alpha}$, then $\underset{\sim}{\alpha} / \partial \theta$ would be near zero.

Because of the uncertainty in $\partial \underset{\sim}{\alpha} / \partial \theta$, the probable smallness of the term, the very approximate nature of this theory from the outset, and because of the simplicity which results, the vector direction of this thermal term will be approximated as $(\underset{\sim}{\sigma}-\underset{\sim}{\alpha}) /|\underset{\sim}{\xi}|$. If the vector direction of $\underset{\sim}{\alpha}$ is approximated to be constant over a time step, then then integrated results for $\underset{\sim}{\alpha}$ and $\mathrm{R}$ between states ( $)_{1}$ and ()$_{2}$ are: 


$$
\begin{aligned}
& \underline{\sim}_{2}=\alpha_{1}+\sqrt{\frac{2}{3}} \cdot\left[\mathrm{H}_{\alpha}\left(\overline{\mathrm{e}}_{\mathrm{p}_{2}}, \theta_{2}\right)-\mathrm{H}_{\alpha}\left(\overline{\mathrm{e}}_{\mathrm{p}_{1}}, \theta_{1}\right)\right]\left(\boldsymbol{\sigma}_{\mathrm{T}}-\underline{\alpha}_{\mathrm{T}}\right) /\left|\xi_{\mathrm{T}}\right| \\
& \text { - } R_{2}=\sqrt{\frac{2}{3} H_{K}}\left(\bar{e}_{p_{\varepsilon}}, \theta_{2}\right)
\end{aligned}
$$

\section{Trial state}

The "trial state" ()$_{T}$ is taken to be the state which would be roached if the process were elastic: 'l'he stress yiven by the elastic part of Eqn. (3) is

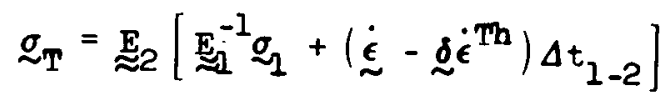

and the yield surface center at the new temperature is

$$
{\underset{\sim}{\mathrm{T}}}_{\mathrm{T}}={\underset{\alpha}{1}}_{1}+\sqrt{\frac{2}{3}}\left[\mathrm{H}_{\alpha}\left(\overline{\mathrm{e}}_{\mathrm{p}_{1}}, \theta_{2}\right)-\mathrm{H}_{\alpha}\left(\overline{\mathrm{e}}_{\mathrm{p}_{1}}, \theta_{1}\right)\right]\left(\boldsymbol{g}_{\mathrm{T}}-\alpha_{\mathrm{T}}\right) /\left|\xi_{\mathrm{T}}\right|
$$

where $\xi_{T}$ is simply the deviatoric part of $\left({\underset{\sim}{T}}_{T}-\underset{\sim T}{\alpha}\right)$.

The normality assumption on the plastic strainrate vectur is now imposed as

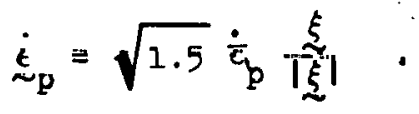

This is integrated with the unit vector approximated as constant uver the step between states ()$_{1}$ and ()$_{2}$ to give the final stress state froil Eyns. (3) and (13) ab:

$$
\boldsymbol{g}_{2}=g_{\mathrm{T}}-\sqrt{6 \mathrm{G}} 2\left(\bar{e}_{\mathrm{p}_{2}}-\bar{e}_{\mathrm{p}_{1}}\right) \xi_{\mathrm{T}} /\left|\xi_{\mathrm{T}}\right|
$$


where the unit vector is approximated to be in the direction of the trial state. This also makes use of the fact that for an "1sotropic material, $\underset{z}{E}$ acting on a deviator is simply $2 \mathrm{G}$ times the deviator where $G$ is the shear modulus.

\section{Consistency Condition}

The consistency condition is now imposed where $s, \underset{\sim}{\alpha}$ and $R$ are to change in such a manner that . remains zero during a plasticity process. This is usually applied in the differential form $=0$. For the numerical work described here; the condition is imposed at the end state ()$_{2} \cdot$

Equations (10), (11), (1,3) and (14) arc aubstituled Into Eqnin. (14) to give $^{1}$ :

$$
\begin{aligned}
& {\left[\tilde{g}_{\mathrm{T}}-\sqrt{6} \mathrm{G}_{2}\left(\overline{\mathrm{e}}_{\mathrm{p}_{2}}-\overline{\mathrm{e}}_{\mathrm{p}_{1}}\right) \xi_{\mathrm{T}} /\left|\xi_{\mathrm{T}}\right|-{\underset{\sim}{\mathrm{T}}}_{\mathrm{q}}-\sqrt{\frac{2}{3}}\left\{\mathrm{H}_{\alpha}\left(\overline{\mathbf{e}}_{\mathrm{p}_{2}}, \theta_{2}\right)\right.\right.} \\
& \left.\left.-\mathrm{H}_{\alpha}\left(\bar{e}_{p_{1}}, \theta_{2}\right)\right\}\left(\sigma_{T}-\stackrel{\alpha}{\sim}_{T}\right) /\left|\dot{\xi}_{T}\right|\right]^{2}=\left[\sqrt{\frac{2}{3}} \mathrm{~B}_{\mathrm{R}}\left(\bar{e}_{\mathrm{p}_{2}}, \theta_{2}\right)\right]^{2}
\end{aligned}
$$

The fact is used that the inner product of a deviatoric vector and an arbitrary vector is equal to the inner product of the deviators of both vectors. The inner product is carried out and the square root taken on both sides to give:

$$
2 G_{2} \bar{e}_{p_{2}}+H\left(\bar{e}_{p_{2}}, \theta_{2}\right)=2 G_{2} \bar{e}_{p_{1}}+\sqrt{1.5}\left|\xi_{T}\right|+H_{\alpha}\left(\overline{\mathbf{e}}_{p_{1}}, \theta_{2}\right)
$$

The terms on the right side are all known while those on the left contain the unknown $\bar{e}_{p_{2}}$. This equation can be solved for $\bar{e}_{p_{2}}$ and substituted into Eqns. (10), (11) and (14) to give finalvalues for $\stackrel{\alpha}{2}_{2}, R_{2}$ and $\sigma_{2}$

1. The square on the left side of Eqn': (15) actually means the inner product of the deviatoric part of the vector inside with itself. 


\section{Numerical Solution Procedure}

In summary, for any given state ${\underset{\sim}{\sigma}}_{1}, \underset{\sim}{\alpha}{ }_{1}, \bar{\varepsilon}_{p_{1}}, \theta_{1}$, and a step size $\Delta$ t with driving rates $\dot{\theta}$ and $\underset{\tilde{\varepsilon}}{\dot{a}}$ approximated to be constant over the step, the following sequence is followed.

i). Look up the values of $\underset{\approx}{\mathrm{E}_{1}^{-1}}, \underset{\approx 2}{\mathrm{E}_{2}}, \mathrm{G}_{2}, \mathrm{H}_{\alpha}\left(\bar{\epsilon}_{\mathrm{p}_{1}}, \theta_{\mathrm{p}}\right), \mathrm{H}_{\alpha}\left(\bar{\epsilon}_{\mathrm{p}_{1}}, \theta_{2}\right), \mathrm{H}_{\mathrm{R}}\left(\bar{\epsilon}_{\mathrm{p}_{1}}, \theta_{2}\right)$.

ii) $\quad$.alsulate $\sigma_{T}$ using Eqn. (12), then find $\underset{\sim T}{\alpha}$ using Eqn. (13) and $\theta_{\mathrm{p}}$ in place of $\theta_{1}$ and simultaneously find $\left|\xi_{\mathrm{T}}\right|$.

iii), check lụ plastioity usingi a mudified form of Eql1. (4), viz,

$$
\psi=\left|\xi_{T}\right|-\sqrt{\frac{2}{3}} H_{R}\left(\bar{e}_{p_{1}}, \theta_{2}\right)
$$

iv) If $\psi \leqq 0$, then $\sigma_{2}=\sigma_{\sim}$ and $\underset{\sim}{\alpha} \dot{\sim}_{2}$ is kept at the value ${\underset{\sim}{\alpha}}_{1}$ and the temperature $\dot{\theta}_{\mathrm{p}}$ left unchanged.

v) If $\psi>0$; then solve Eqn. (16) for $\bar{e}_{\mathrm{p}_{2}}$. Use Eqn. (14) to find ${\underset{\sim}{2}}_{2}$ and Eqn. (10) with $\theta_{p}$ in place of $\theta_{1}$ to find $\underset{\sim}{\alpha}$. Replace $\theta_{\mathrm{p}}$ with $\theta_{2}$.

The quantities to be stored are $\sigma_{2}, \underset{\sim}{\alpha}, \bar{e}_{p_{2}}$, and $\theta_{p}$ at each

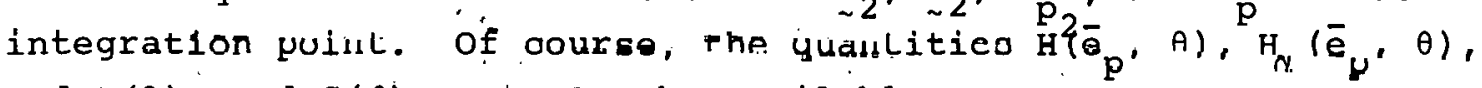
and $\underset{\approx}{E}(\theta)$, and $G(\theta)$ must also be available.

If $\mathrm{H}_{\alpha}$ is not a function of temperature, the computation time for the calculations is shortened considerably, perhaps halved. This is oauser hy the difficulty in finding $\underset{\sim T}{\alpha}$ for lle thermal case since $\left|\xi_{T}\right|$ is required for this calculation. The analyst is definllely encouraged to make this approximation when possible.

\section{Applicability of the Model}

Use of the function $\mathrm{H}\left(\bar{e}_{\mathrm{p}}, \theta\right)$ requires some engineering judgment. The function can be fitted so well to a loading curve from a uniaxial stress test that the user is lulled into thinking that the model is achieving this accuiacy everywhere. This accuracy, in fact, can only be achieved for monotone uniaxial stress loading and even then variations of the same alloy between suppliers, between heats from the same supplier; and between samples from the same plate are often 
surprisingly large. This is a defect in the basic hardening model: proposed by Hodge.

Within the variation between the actual part being analyzed and the material test specimen, the model is quite realistic if the loading is nearly radial and never undergoes reverse plastic straining. The behavior during pure radial loading rests on the accuracy of the von Mises yield surface. For an initially isotropic material, this should be generally within about ten percent. If the material loads plastically, unloads elasticaliy and then reloads plastically in nearly the same direction, the model behaves fairly well; but if the loading is in a different direction, then the accuracy of the model deteriorates with or without an interruption of the loading. This is illustrated for the uniaxial stress case in Figure. 1. The model can be made to fit the experiment quite well out to point $A$, even with the elastic unloading. But on reverse plastic loading, the model only captures the gross behavior. This is because the plastic portion of the reverse stress-strain curve is only a continuation of the loading curve. For the model $M_{1}$ in the figure, the functions $H_{\alpha}$ and $H_{R}$ were chosen such that an indicator could be set to signal poor subsequent behavior of the model: This could be set if $\underset{\sim}{\alpha} \neq \underset{\sim}{0}$ and $\underset{\sim}{\sigma} \sigma_{T} \underset{\sim}{\alpha}<0$. ' If reverse loading is necessary, then $H_{\alpha}$ and $\tilde{H}_{R}$ should be chosen as in model $\mathrm{M}_{2}$ shown in Figure 1 . The average reverse loading is followed as best the model can handle this.

'rhis basic defect in Hodge's combined 1sotropic-kinematic hardening model has been known and accepted for many years. The present treatment neither helps nor enhances the defect. This section is simply included as a reminder of its presence.

Non-Thermal Linear Hardening Illustrated

A numerical method for solving the equations of plasticity for the therinal. case has been presented and this is the form in which it will probably be used. It is instructive, however, to strip away as much of the algebra as possible in order to look at the essentials 
of the model. The simplicity of the method is best illustrated for the non-thermal case where a linear plastic hardening slope is used.

$$
\begin{aligned}
& \mathrm{H}_{U}=(1=\beta) \bar{R}_{\mathrm{p}} \\
& \mathrm{H}_{\mathrm{R}}=\beta \overline{B \bar{e}}_{\mathrm{p}}+\mathrm{Y}_{0}
\end{aligned}
$$

where $B$ is calculated from the elastic $E$ and plastic $E_{p}$ moduli from a uniaxial stress test as $\mathrm{EE}_{\mathrm{p}} /\left(\mathrm{E}-\mathrm{E}_{\mathrm{p}}\right)$ and $0 \leq \beta \leq 1$ to control the isotropic-kinematic behavior. $Y_{0}$. is the inttlal uniaxial yield stress.

The trial stress state is found from Eqn. (12) as

$$
\underline{\sim}_{T}=g_{1}+\underset{\approx}{\mathbf{\epsilon}} \Delta t_{1-2}
$$

and $\varphi_{T}$ foynd from Eqn. (4) to determine whether the step was indeed elastic $\left(\varphi_{\mathrm{T}}\right.$ was non-positive and so $\left.\underset{\sim}{\sigma_{2}}={\underset{\sim}{\sigma}}_{\mathrm{T}}\right)$. If $\varphi_{\mathrm{T}}>0$, then the effective plastic strain step is found from Eqn. (16) as

$$
\Delta \bar{e}_{p}=\frac{1}{\sqrt{6 C}} \quad \frac{\left|\xi_{T}\right|-R_{1}}{1+\frac{B}{3 G}}
$$

where $R_{1}$ is $R_{0}+2 / 3 \mathrm{Be}_{\mathrm{F}_{1}}$. The final state is found from Eqns. (14) and $(10)$ as :

$$
\begin{aligned}
& g_{2}=g_{\mathrm{T}}-\sqrt{6 \mathrm{G}} \dot{\overline{\Delta e}}_{\mathrm{p}} \xi_{\mathrm{T}} /\left|\xi_{\mathrm{T}}\right| \\
& \stackrel{\alpha}{2}_{2}=\alpha_{1}+\sqrt{\frac{2}{3}}(1-\beta) B \overline{\Delta \bar{e}}\left(\sigma_{\mathrm{p}}-\underline{\alpha}_{1}\right) /\left|\dot{\sim}_{\mathrm{T}}\right| \\
& \bar{e}_{p_{2}}=\bar{e}_{p_{1}}+\Delta \overline{e_{p}}
\end{aligned}
$$

In this case, only one square root is required (the magnitude of $\left.\xi_{T}\right)$ and the four algebraic. Eqns. $(18)-(21)$ constitute the extra work required if plasticity is present. . 


\section{DISCUSSION}

The accuracy of the non-thermal case with no hardening has been examined $[8]$ and compared with other numerical methods of integrating these same plasticity equations. All of the methods studied give exact results in the limit as the strain step size goes to zero. The present method in contrast to the other methods also asymptotically approaches the exact result for a constant strainrate vector as the strain step size becomes large: For moderate strain step sizes other methods are just as accurate and in fact may be more accurate in certain regions of strain step sizes and step directions. The main advantage of the present method is its computatinnal speed.

The non-thermal model was incorporated into the two dimensional dynamic structural computer program HONDO $[9]$. Two problems were run, both with a conventional tangent method and with the radial return method presented here. Only the constitutive subroutine was changed. for these comparisons.

The first problem was a thick short cylinder with a uniform outward radial velocity. The velocity was such that all points were yielding most of the time. This problem required $5605 \mathrm{C} . \mathrm{P}$. sec on the CDC 6600 with the conventional tangent method and $3936 \mathrm{C} . \mathrm{P}$. sec with the new radial return method. This was a 30 percent savings in time or over $\$ 100$ savings in money.

The second problem was a long bar struck on one end with a larqe suddenly applied pressure. The plasticity in this problem was very localized. There was only a seven percent overall savings in time for this problem.

An internal measurement was made with the second problem on the time spent in the plasticity loops of the respective constitutive subroutines. This showed that the tangent method required roughly three times as long to do the plasticity calculations as the radial. return method presented here.

The accuracy of the two methods must have been very adequate. Differences in stresses and displacements between the two methods were less than 0.18 of the maximum values. 


\section{SUMMARY}

A numerical method has been presented for the solution of a rather conventional time independent plasticity model. It is particularly applicable to the quasistatic nearly radial loading problem. The non-thermal linear hardening case is also illustrated. For the two test cases which were run, the new method gave virtually the same results as a more conventlonal method. "The plasticity computations . arc roughly three times as fast with the present method than those using a conventional methud. 


\section{LIST OF REFERENCES}

1. Armen, H. A., Jr., "Plastic Analysis," Structural Mechanics Computer Programs Surveys, Assessments and Availability, ed.

W. Pilkey, K. Saczalski, and H. Schaeffer, Univ. Press of Virginia, Charlottesville, 1974, pp. 37-39.

2. Desai, Suresh K., "Summary of.General Purpose Programs," Shock and Vibration Computer programs Reviews and Summaries, ed. Walter and Barbara Pilkey, Univ. of Virginia, Charlottesville, 1975, pp. 529-536.

3. Fung, Y. C., Foundations of Solid Mechanics, Prentice-Hall, Inc., Englewood Cliffs, N.J., 1965, pp. 140-141.

4. Hodge, P. G., Jr., Discussion of Prager (1956), J. Appl. Mich., Vol. 24,1957 ; pp. $482-483$.

5. Goell, R. P. and I. E. Malvern, "Biaxial Plastic Simple Waves with Combined Kinematic and Isotropic Hardening," J. Appl. Mich., Vol. 37, 1970, pp. 1100-1106.

6. Phillips, Aris and Juh-Iing Tang, "The Effect of Loading Path on the Yield Surface at Elevated Temperature," Int. J. Solids Structures, Vol. 8, 1972, pp. 463-474.

7. Hecker, S. S., "Influence of Deformation History on the Yield Locus and Stress-Strain Behavior of Aluminum and Copper," Met. Trans., Vol. 4, Ap 1973, pp. 985-989.

8. Krieg, R. D. and D. B. Krieg, "Äccuracies of Numerical Solution Methods for the Elastic-Perfectly Plastic Model," to be published.

9. Key, S. W., "HONDO, a Finite Element Computer Program for the Large Deformation Dynamic Response of Axisymmetric Solids," SLA-74-0039, Sandia Laboratories, Albuquerque, New Mexico, (Jan. 1.974). 
FIGURE 1. Stress-strain curve for a real material modeled for two differnt purposes.

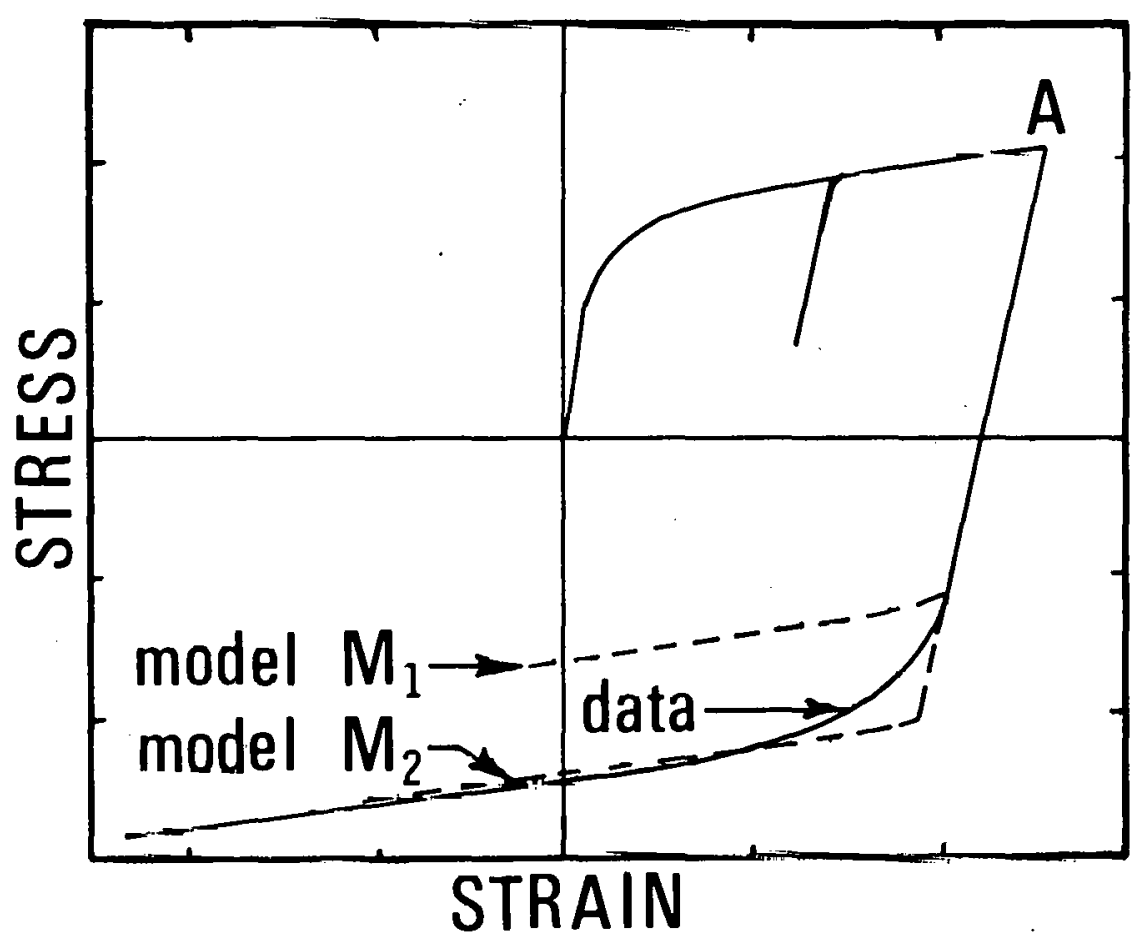




\section{DISTRIBUTION :}

1281 R. D. Krieg (20)

8266 - E. A. Aàs

3141 C. A. Pepmueller (Actg) (5)

3151 W. L. Garner (3)

For DOE/TIC (Unlimited Release)

DOE/TIC (25)

(R. P. Campbell, 3171-1) 